This fact is connected in some way with the internal secretion of the kidney. Herter, in an analysis of 41 cases of suppression due to stone, says that convulsions occurred in only five cases, headache in six, and vomiting in 12 . As regards the duration, cases are on record where no urine was passed for more than a fortnight. In one case in which the only kidney was removed the patient survived 11 days.

And now let us turn for a moment to the most interesting point. Dr. Dukes asks, "Can a stone in one ureter inhibit the action of both kidneys?" I hold strongly that it can. Two cases that have come under my care during the past year bear upon this question.

In the first, that of an elderly man suffering from malignant disease of the prostate, total suppression came on suddenly. The left kidney was opened from the loin, the obstruction being due to a small stone. Subsequently he passed much urine and on his death six weeks afterwards the right kidney was found to be healthy.

The second case is not so conclusive, as we were fortunately not able to verify the condition post mortem. A young man after having suffered from attacks of renal colic for five years was seized with suppression. On the fourth day the left kidney was opened and a probe was passed down it into the bladder but no calculus was found. He made an uninterrupted recovery and at the end of six weeks was discharged with the nephrotomy wound healed and passing 50 ounces of urine in the 24 hours. The anuria in this case was, $I$ think, probably brought about by a kink in the left ureter which was put right by the manipulation and subsequent fixation of the kidney. It may possibly have been due to a stone which I failed to detect but which escaped during the operation. In neither of the cases was there any dilatation of the pelvis, nor was there anything to point to disease of the opposite kidney.-I am, Sirs, yours faithfully,

Lancaster, July 18th, 1904.

A. S. BARLing.

\section{ON THE POSSIBLE LOCAL NATURE OF SCARLET FEVER.}

To the Editors of THE LANCET.

Strs,--The cause of scarlet fever is generally assumed to be a micro-organism circulating in the blood. 'There is much evidence in support of the micro-organism, but as far as can be ascertained little or none with regard to its habitat being the circulation. On the other hand, I think there is much evidence in support of the view that scarlet fever is a local faucial disease which produces its characteristic symptoms by means of absorbed toxins. The confirmation or refutation of this local theory is, of course, dependent upon exact bacteriological knowledge, which up to now is not forthcoming. Dr. M. Gordon's summary in the "Encyclopædia Medica", gives the bacteriology up to date and though somewhat indefinite, yet, when taken in conjunction with the obviously infectious nature of the disease, it makes a very strong case for the assumption that the streptococcus conglomeratus is the real cause of the disease. This microorganism is found in the faucial mucus and nasal discharge, but not in the aural discharge. It is also found in the exudates and in the blood of patients dying from the disease. The absence from the aural discharge is probably due to the ordinary pus cocci, so to speak, getting the victory. Thus far, then, the bacteriology apparently supports the view that the disease is due to a blood infection. The presence of the streptococcus conglomeratus in the exudates implies a transitory passage in the circulation or lymphatic system. The finding of the organism itself in the blood by no means proves that the circulation is the place where it multiplies and produces its toxins. There are other diseases which we know to be local in which the specific micro-organism has been found in the blood in numbers. Moreover, the clinical features of the disease are somewhat against the blood infection view. It is well known that the rash of scarlet fever almost invariably starts on the neck and chest and thence spreads over the body and less markedly upwards over the face and head. The extension of the rash on to the face is not mentioned by all authors but it undoubtedly does occur and is evident if the case is seen early enough. The early desquamation of the face must imply previous rash. This constant point of onset and definite slow march over the body, so much slower than the progress of the blood, is one of the most constant and remarkable features of the disease. To my mind it implies a constant point from which the toxin is absorbed and a vehicle other than the blood. On looking at the disposition of the lymphatic system and its relation to the tonsils and pharynx it will be seen that the absorption of a rash-producing toxin along these channels would be most likely to give rise to its earliest effects in the neighbourhood of the neck and chest. The enlargement of the glands in the region of the neck is evidence that absorption of some kind is taking place. The blood infection theory cannot in any way explain the rash, for if that theory be true one would expect an irregular rash, making its onset at no particular point and becoming patchy or else a rash which pervades the whole body and gradually deepens.

If the course of the disease be compared with the severity of the initial angina it will be found that there is a very definite relation between them. That is to say the more severe the throat symptoms the more pronounced and enduring will be the rash and the more severe the early course of the disease. This applies only to the early angina and not to the severe faucial inflammation which often supervenes, this latter being due to secondary infection. These conclusions embody observations on some hundreds of cases, but to confirm them I wrote a letter to a number of medical officers of infectious hospitals asking the following questions: 1 . In your experience is there any definite relation between the intensity of the initial throat symptoms and the intensity of the rash in scarlet fever? 2. Does the intensity of the subsequent peeling vary with the intensity of the rash, with its persistence, or with both? To the first question I received seven replies in the affirmative and two in the negative. One reply in the negative had a note added to the effect that the throat symptoms depended largely upon the hygienic or unhygienic state of the oral cavity, which rather implies that the answer was meant for the secondary angina. So that there is much evidence to show that throat and rash bear a definite relation to one another. To the second question all the replies stated that the intensity of the peeling depends upon both the intensity and persistence of the rash, but chiefly the former.

Clifford Allbutt, in his "System of Medicine," looks upon the greater prevalence of scarlet fever in the northern hemisphere as being due to the greater prevalence of enlarged tonsils.

In diphtheria we have a throat disease of undoubted local nature, and if scarlet fever is looked at side by side with this disease it will be seen how remarkably alike are the symptoms and sequelæ, the difference being largely those of intensity, time, or frequency of occurrence.

\begin{tabular}{c|c|c}
\hline Disease. & Initial symptoms. & Sequelæ. \\
\hline Scarlet fever. & $\begin{array}{c}\text { Throat and nose; } \\
\text { rash. } \\
\text { Diphtheria. }\end{array}$ & $\begin{array}{c}\text { Albuminuria, arthritis, cardiac, } \\
\text { otitis, adenitis, neuritis. } \\
\text { Tlbuminuria, arthritis, cardiac, } \\
\text { otitis, adenitis, rash, neuritis. }\end{array}$
\end{tabular}

If scarlet fever is a local disease it will certainly follow that the desquamating epithelium is not in itself infectious, that is to say, only becomes infectious from contamination with faucial or nasal discharges. Desquamation of a mild kind of course is a natural process and can be easily observed in the uncleanly and it only requires conditions of hyper. æmia, malnutrition, or circulating toxins to bring about pathological desquamation. It may be seen after many diseases and is in no sens $\approx$ a criterion of scarlet fever. It has been seen after typhoid fever, acute rheumatism, measles, and after rashes produced by toxins absorbed through the intestinal canal. With regard to the non-infectious nature of desquamation after scarlet fever, Dr. C. K. Millard produced some very interesting evidence in THE LANCET of April 5th, 1902 , p. 959. His principal arguments against the infectious nature of the desquamating epithelium are as follows: (1) the absence of evidence supporting it; (2) infection begins prior to desquamation and often continues long after desquamation has ceased; (3) scarlet fever wards thongh abounding in desquamating epithelium are not a danger to neighbouring houses; and (4) the proportion of "return" cases does not appear to be increased amongst patients sent out from hospital still desquamating.

There is just one point that requires explanation and that is the apparent flaw in the argument caused by the fact that in scarlatina maligna one may get no rash or throat 
symptoms; the patient may die within 24 hours of onset. It seems to me that in these cases there are all the appearances of a blood infection pure and simple and that the condition is one of scarlatinal septicæmia.

To sum up, then, the bacteriological evidence, the very definite relation between the severity of the throat symptoms and the severity of the rash, the remarkable similarity of this disease to that of diphtheria, and the evidence supporting the view that the desquamating epithelium is not the infecting material, all these point to the disease being local rather than general. To this may be added the fact that the blood infection view cannot explain the onset and progress of the rash in a satisfactory manner.

I am, Sirs, yours faithfully

July 18th, 1904.

A. H. Gerrard, M.B. Lond.

\section{WHAT CONSTITUTES LIVE BIRTH?}

\section{To the Editors of THE LANCET.}

SIRs,-The definition of stillbirth, proposed by the Midwives Board and later authorised by the Privy Council, as quoted under the above title in THE LANCET of July 9th, p. 93, should not be allowed to pass without comment. The tests applied by midwives are to be "breathing or showing any sign of life after being completely born." This definition makes stillbirth and deadbirth identical, whereas historically and not uncommonly in books and in practice these terms are opposed. The stillborn is really the silentborn child (compare "the still days" of Passion week); these newly-born children are not necessarily pulseless, that is, asphyxiated in the true sense of that word. Further, "any sign of life" begs the whole question, for this requirement is an alternative far too indefinite to be allowed place in a logical definition. This easy vagueness gives ample scope for such casuistry as was exemplified in the oft-quoted cáse Fish $v$. Palmer (not reported), where a full-term child was born in 1796 and was stated by the nurse to have exhibited, as a sign of postnatal life, no other token than "twice a twitching and tremulous motion of the lips"; the jury decided for its live birth. Such a remarkable test case meeded severe scrutiny and verification. I decided to trace its literary history with the following result. The English text-book authors all quote it from Beck, he quoted it from Fiodéré, who quoted it from $L e$ Moniteur, whither it was copied and translated from Lloyd's Evening Post of July 15th, 1806. This was its original citation with three other identical accounts, presumably from the same pen, in three contemporary newspapers-the Times being silent. Since the learned reporter has long been disabled from making affidavits as to the accuracy of his report, the alleged decision must remain of very little forensic significance ; indeed, it has never been cited by counsel. Decided cases, civil and criminal, show that the postnatal continuance of activity of the cardio-vascular system is the essential minimum for live birth. Mr. Justice Wright has personally assured me that he "has no objection" to the terms he is stated to have used in defining "separate existence in the theory of the law." Finally, may I quote, as a curiosity, a death certificate returned in 1896 in which the subject was stated to be "aged one minute"?

I am, Sirs, yours faithfully,

Inner Temple. July 11th, 1904. ST ANLEY B. ATKINson.

\section{THE WHITE CROSS LEAGUE.}

To the Editors of THE LANCET.

SIRs,-The satisfactory results of the mission to the principal towns and cantonments in India undertaken by the White Cross League two years ago have made the committee desirous of complying with the request of the Bishop of Lahore, the president of the Indian White Cross Association, to send out one of its staff again this winter. The ready welcome given to the speaker sent out by the leagu 3 by every branch of the service and the earnest coöperation of officers and men gave vivid proof of the spirit that is at work in the army in India and throws on us a fresh obligation to meet effectively so remarkable a response. It would be a serious thing to miss an opportunity to which so high an authority again invites us, yet it is impossible for us to accept the call on the strength of our present scanty funds. These are already inadequate to meet the growing demands upon our resources for work at home. We are therefore obliged to appeal for assistance to those of the public who are interested in the moral welfare of our countrymen in India, which in these davs of short service is closely connected with our home life and national health. No one who realises the moral strain which the national will lays upon our Indian army can hold himself unconcerned in its welfare or unaware of its perils. By assisting the league he may do something to discharge this responsibility towards those who have to maintain the nation's honour at such terrible risk. As the absence of one of its secretaries from Fngland for five or six months will necessitate the employment of a substitute the total amount required will be at least $£ 150$. Any donation will be thankfully received by the committee and may be sent to the secretaries of the White Cross League at 7 , Dean's-yard, Westminster, by whom any detailed information will be gladly supplied.

We are, Sirs, yours faithfully,
A. LUCKNOW, Bishop.
RoBERTS,
Field-Marshal.
J. WOLFE MURRAY
Major-General. H. M. EvaNs, C.B.,
HENRY SCOTT HoLLAND, Vice-Chairman.
G. A. LAHORE,
Bishop, President Indian
Army White Cross Association.

\section{CONTAGIOUS ABORTION IN CATTLE.} To the Editors of THE LANCET.

SIRs, - In your note on the above subject in THE LANCE'T of July 16th you observe: "Professor Cave's results clearly show that contagious abortion can be prevented by the adoption of appropriate locel antiseptic treatment for cows and, if necessary, for the bull." I have italicised the last statement because I am surprised to see any doubt expressed as to the need for treating the bull in every herd in which contagious abortion (warping) has established itself. My impression is that the late Professor Nocard clearly established nearly 20 years ago that in every such case the bull was the main, if not the sole, medium for diffusing the infection and some inquiries which I myself made in this neighbourhood more than ten years ago quite confirmed that opinion.

I am, Sirs, yours faithfully,

Gloucester, July 18th, 1904. FRANCIS T. BoND, M.D. Lond.

\section{To the Editors of THE LANCET.}

SIRS, - I have read with much interest your annotation in THE LANCET of July 16th concerning the local use of antiseptics as a remedy for recurring abortion in cattle. I am under the impression that the treatment is not so new as your reference to Professor Cave's experiments would lead your readers to believe since it is within my knowledge that at least one veterinary surgeon of distinguished standing in his profession and a famous breeder of prize cattle- $\mathrm{Mr}$. $\mathrm{C}$. Stephenson of Newcastle-upon-Tyne-has for years made use of antiseptic vaginal injections with marked success in the treatment of such cases.

Newcastle-upon-Tyne, July 19th, 1904. WILITAM MARTIN, M.D. Durh.

\section{THE INTERNATIONAL CONGRESS OF DERMATOLOGY.}

To the Editors of THE LANCET.

SxRs, - You were kind enough some time back to call the attention of your readers to the report I was preparing for the forthcoming Berlin International Congress of Dermatology on Prevalence of Leprosy in the British Empire. May I ask you to be kind enough to let me notify in your columns my thanks to the numerous correspondents who have sent me data, and greatly oblige

Yours faithfully,

GEORGE PERnet,

July 18th, 1904

Assistant to the Skin Departmen University College Hospital.

\section{LAYMEN AND ELECTRICAL TREATMENT.}

\section{To the Editors of THE LANCET.}

SIRS,-It is unfortunately the practice of many members of the profession to send patients whom they may wish to be treated by some form of electricity or the $x$ rays either to a layman for this purpose or to an institution owned and 